NBER WORKING PAPER SERIES

\title{
ARE THE RICH MORE SELFISH THAN THE POOR, OR DO THEY JUST HAVE MORE MONEY? A NATURAL FIELD EXPERIMENT
}

\author{
James Andreoni \\ Nikos Nikiforakis \\ Jan Stoop \\ Working Paper 23229 \\ http://www.nber.org/papers/w23229 \\ NATIONAL BUREAU OF ECONOMIC RESEARCH \\ 1050 Massachusetts Avenue \\ Cambridge, MA 02138 \\ March 2017
}

We would like to thank Olivier Bochet, Zachary Breig, Aurélie Dariel, Robert Dur, PJ Henry, Steven Levitt, John List, Drazen Prelec, Travis Proulx, Vitalie Spiny, Darjusch Tafreschi, Joost Verlaan, Pepijn Pest, participants in seminars at Berlin Social Science Center, Erasmus University, Kiel University, New York University Abu Dhabi, Tilburg University, the University of Athens, the University of Chicago, the University of Nottingham, and Wageningen University, and conference participants of FUR, TIBER, and SPI for useful comments. We are also grateful to ERIM and NWO (Veni grant 016.155.026), the National Science Foundation (grants SES-1427355 and SES-1658952 to Andreoni), the Science of Philanthropy Initiative, and the John Templeton Foundation (to Andreoni) for financial support. The authors acknowledge access to linked data resources by the Central Bureau of Statistics Netherlands. Researchers hoping to use the data found in this article can apply for access to CBS. The authors of this paper are willing to offer guidance about the application. The views expressed herein are those of the authors and do not necessarily reflect the views of the National Bureau of Economic Research.

NBER working papers are circulated for discussion and comment purposes. They have not been peer-reviewed or been subject to the review by the NBER Board of Directors that accompanies official NBER publications.

(C) 2017 by James Andreoni, Nikos Nikiforakis, and Jan Stoop. All rights reserved. Short sections of text, not to exceed two paragraphs, may be quoted without explicit permission provided that full credit, including $\odot$ notice, is given to the source. 
Are the Rich More Selfish than the Poor, or Do They Just Have More Money? A Natural Field

Experiment

James Andreoni, Nikos Nikiforakis, and Jan Stoop

NBER Working Paper No. 23229

March 2017

JEL No. C93,D63,D64

\section{ABSTRACT}

The growing concentration of resources among the rich has re-ignited a discussion about whether the rich are more selfish than others. While many recent studies show the rich behaving less prosocially, endogeneity and selection problems prevent safe inferences about differences in social preferences. We present new evidence from a natural field experiment in which we "misdeliver" envelopes to rich and poor households in a Dutch city, varying their contents to identify motives for returning them. Our raw data indicate the rich behave more pro-socially. Controlling for pressures associated with poverty and the marginal utility of money, however, we find no difference in social preferences. The primary distinction between rich and poor is simply that the rich have more money.

James Andreoni

Department of Economics

University of California, San Diego

9500 Gilman Drive

La Jolla, CA 92093-0508

and NBER

andreoni@ucsd.edu
Jan Stoop

Department of Applied Economics

Erasmus School of Economics

PO Box 1738

3000 DR Rotterdam

The Netherlands

stoop@ese.eur.nl

Nikos Nikiforakis

New York University Abu Dhabi

Social Science Division

P.O. Box 129188

Abu Dhabi, United Arab Emirates

nikos.nikiforakis@nyu.edu

An Online appendix is available at http://www.nber.org/data-appendix/w23229 
Ernest Hemingway: "I'm getting to know the rich."

Mary Colum: "The only difference between the rich and other people is that the rich have more money."1

\section{Introduction}

Are the rich more selfish than others? One often finds claims in the popular press, political discourse, classic literature, pop music, and even the Bible, suggesting many believe that being rich, almost by definition, means that one has little regard for others. ${ }^{2}$ The recent financial crisis and the evidence that, in its aftermath, the inequality between the rich and poor has grown further (Saez and Zucman, 2016), seem to have rekindled this belief (e.g. Goleman, 2013; Proud, 2015). The growing concentration of the world's resources among the very rich (Atkinson et al., 2011), their disproportionate influence on public policy (Fuentes-Nieva and Galasso, 2014), and the increased reliance on their benevolence for the provision of goods and services that were once the near sole province of governments such as higher education and health (Andreoni and Payne, 2013; Sullivan, 2017), all imply that knowing whether the rich are indeed more selfish than the less well-off is potentially of great importance.

The empirical evidence, at first pass, seems to present an indictment of the rich, pointing towards a rampant skulduggery. They evade and avoid more taxes than others (Cox, 1984; Christian, 1994; Wang and Murnighan, 2014), they are less likely to donate to charity in any given year (Auten et al., 2002), and more likely to break the law when driving (Piff et al., 2012). While this evidence is clearly indicative of selfish behavior, it cannot support claims that the rich are more selfish than others due to endogeneity problems. Wealth affects individual incentives, which in turn affect pro-social behavior. For instance, the rich have less difficulty paying any given traffic ticket than others due to the diminishing marginal utility of income; they face higher marginal tax rates and thus have greater incentives to evade or avoid taxes; they are more likely to have self-employment income, passive income, and capital gains, and thus have more opportunities to shield or even hide income (Roth et al., 1989); and while they give less frequently to charity, they also tend to give larger sums when they do, appearing to "save up" for more impactful donations (Schervish and Havens, 2003). ${ }^{3}$ Due to the endogeneity problem, differences in the pro-social behavior between rich and others

\footnotetext{
${ }^{1}$ This exchange between Hemingway and Colum is reported in Berg (2016).

${ }^{2}$ There are several notable examples. For instance, Jesus is quoted in the Bible saying: "It is easier for a camel to go through the eye of a needle than for a rich man to enter the kingdom of God." (Mark 10:25). The 7th President of the USA, Andrew Jackson, is quoted as saying: "It is to be regretted that the rich and powerful too often bend the acts of government to their own selfish purposes." Similarly, the 32nd President of the USA, Franklin Delano Roosevelt, remarked that "[w]e must especially beware of that small group of selfish men who would clip the wings of the American Eagle in order to feather their own nests." In popular music, John Lennon, in his song "Working Class Hero", sang: "There's room at the top they are telling you still, but first you must learn how to smile as you kill."

${ }^{3}$ For a review on the relation between wealth and tax compliance see Andreoni et al. (1998). For reviews on the relation between wealth and charitable giving, see Andreoni (2006) and Andreoni and Payne (2013).
} 
cannot readily be attributed to differences in social preferences. In other words, these findings cannot rule out the possibility that, if the rich and the poor were to magically switch places, that each might, Pygmalion-like, behave just like the other did.

Comparing the pro-sociality of the rich with that of others poses several challenges. There is considerable evidence showing that pro-social behavior responds to changes in individual incentives and circumstances, which are likely to differ for the rich. For instance, laboratory experiments indicate that giving to others is affected by the cost of giving (Andreoni and Miller, 2002; Fisman et al., 2007; Karlan and List, 2007), how income is earned (Konow, 2000; Erkal et al., 2011), one's social reference group (Andreoni and Bernheim, 2009; McDonald et al., 2013; Andreoni et al., 2015), and the degree of the giver's anonymity (Hoffman et al., 1996; Andreoni and Petrie, 2004). This implies that any empirical study exploring the relative pro-sociality of the rich must not only isolate the benefit that pro-social behavior confers upon others from the cost of that behavior, but it must also limit the influence of social pressure, social signaling, and other environmental factors that could distort pro-social choices. It should also ensure that the pro-social act is both comparable and attainable for rich and poor alike. ${ }^{4}$ Finally, the research design must ensure that selection into the study does not differentially affect the estimates for the poor and the rich.

We present the first evidence from a natural field experiment examining whether the rich are more selfish than the less well-off. ${ }^{5}$ Our research strategy has several advantages. First, the natural field experiment avoids selection effects. This is especially important given that the rich are underrepresented in most empirical studies, raising questions about the generalizability of any findings (Andreoni, 2006). Second, since participants are unaware they are taking part in an experiment, we avoid demand effects (e.g. Levitt and List, 2007; Camerer, 2015). This is also important as the rich may react differently to social pressure (e.g. DellaVigna et al., 2012). Third, we observe actual pro-social acts and do not have to rely on self-reports (cf. Korndörfer et al., 2015; Trautman et al., 2013). Fourth, the experimental task allows us to disentangle the benefit of the pro-social act from its cost, and ensure that it is both attainable and comparable for all participants. Fifth, we are able to obtain householdlevel data from CBS Netherlands (including disposable income, family size, state benefits, age, and others) which we link to our experimental data to evaluate the robustness of our findings. Although our design overcomes several of the common inference problems arising

\footnotetext{
${ }^{4}$ For example, if a rich and a poor person help an elderly woman cross the road, the gesture is attainable and comparable. However, a donation of $\$ 1,000$ may not be possible for a poor person. Even if it is, it can be difficult to compare the relative generosity of giving $\$ 1,000$ for a rich and a poor person. As a case in point, in 1995 billionaire Walter Annenberg's $\$ 120$ million donation to the University of Pennsylvania was overshadowed by a relatively meager donation of $\$ 150,000$ to the University of Southern Mississippi. The reason is that the later donor, Oseola McCarthy, was an elderly woman with a sixth-grade education who spent her life working as a washerwoman. Tellingly, McCarthy is named in the "Philanthropy Roundtable's Hall of Fame", while Annenberg is not.

${ }^{5}$ In section 2, we review lab and survey studies exploring the pro-sociality of rich and poor. While most of them suggest a negative relationship between wealth and pro-sociality, we will see that the evidence is far from conclusive.
} 
when studying the relationship between wealth and pro-sociality, we cannot fully rule out issues of endogeneity. We address them by making some simple structural assumptions, which allow us to evaluate whether the social preferences of the rich differ from the poor.

The experiment was conducted in the Netherlands where wealth inequality is among the highest in the world (Economist, 2014). To address our research question, we used the "misdirected letter technique" (e.g. Howitt et al., 1977; Franzen and Pointner, 2012; Stoop, 2014) where we purposefully "misdeliver" envelopes to pre-selected households and observe whether the envelopes are returned. The false recipients face no risk by retaining the envelopes, while returning them involves opportunity and other costs. Since returning an envelope benefits the rightful recipient, returned envelopes show costly pro-social behavior. To better understand the driving forces of pro-social behavior in our sample, we use semi-transparent envelopes (see section 3) and vary their contents. ${ }^{6}$ In all conditions, the envelopes include a greeting card from a grandfather to his grandson. In addition, depending on the treatment, envelopes also contained either a $€ 5$ bill, a $€ 20$ bill, a bank transfer card for $€ 5$, or a bank-transfer card for $€ 20$. Bank-transfer cards can only be used by the intended recipient, thus, keeping them does not benefit the false recipient.

As we explain in section 3, our sample consists of 180 rich and 180 poor households. These households are among the richest and poorest in the medium-sized city where the study took place. According to household-level data obtained from the Central Bureau of Statistics Netherlands (henceforth, CBS Netherlands), the rich households in our sample have an average declared wealth of $€ 2,496,629$, whereas the poor households have an average declared wealth of $€ 27,236$. For comparison, the average wealth in 2012 according to CBS Netherlands was $€ 157,000$.

There are different reasons for comparing the pro-sociality of the rich to that of the poor. First, our study can tolerate only a relatively modest sample size. For statistical purposes, it is therefore desirable to use a fairly homogeneous comparison group such as the poor who can be relatively easily identified from their housing. Second, like the rich, the poor are a group for whom a lot has been written regarding their kindness and generosity, often in direct comparison to the rich. ${ }^{7}$ This, along with a growing literature on the effects of poverty on individual behavior (e.g. Mani et al., 2013; Haushofer and Fehr, 2014) makes the poor an interesting group to study in their own right. Third, surveys conducted by psychologists suggest that there may be a negative relation between wealth and one's ability to feel empathy or compassion towards others (Kraus et al., 2012). Given the link between

\footnotetext{
${ }^{6}$ Envelopes of the kind used in our experiment are often used in the Netherlands by the mail company, as well as to send greeting cards.

${ }^{7}$ For instance, in the Bible, in stark contrast to his condemnation of the rich and their exclusion from "the kingdom of God", Jesus is quoted as saying to his disciples: "Blessed are you who are poor, for yours is the kingdom of God." (Luke 6:20). Similarly, in his novel "Le Bal de Sceaux", the famous French author Honoré de Balzac writes: "As a rule, only the poor are generous; the rich have always excellent reasons for not handing over twenty thousand francs to a relation."
} 
empathy, compassion, and pro-social behavior (e.g. Eisenberg et al., 1989), these findings suggest a possible explanation why, all else equal, the rich could behave more selfishly than others. $^{8}$

Our findings strongly contradict the popular view that the rich behave more selfishly than the poor. We show that the rich return 81 percent of the envelopes across treatments. In fact, they are more than twice as likely to do so than the poor (38 percent). The difference is unaffected when we control for a broad range of household characteristics. This finding is surprising given the popular perception about the rich and the lack of repercussions of retaining envelopes. We also find clear evidence that the poor are less likely to return envelopes containing bank-transfer cards the further away they get from their last pay day, suggesting that pro-social behavior may be crowded out by financial pressures. To address the problem of endogeneity, we use a simple structural model controlling for the effects of financial pressure and differences in the marginal utility of income. The estimations suggest that the social preferences of the rich and the poor are indistinguishable. That is, both groups have equally pro-social intentions, but the poor act less pro-socially due to forces created by the fact that they simply have less money.

We perform a number of checks to establish the robustness of our findings. First, we use socioeconomic information about households provided by CBS Netherlands to check that randomization to treatment was successful. Second, we control for this socioeconomic information in our regression analysis. Third, we perform tests to ensure that the mail company is not withholding returned envelopes. Fourth, we conduct surveys with poor individuals to establish that they regularly check their mailboxes and know how to return misdelivered mail. Fifth, we run an additional treatment, with poor households only, in which the text on the greeting card makes it clear that the intended recipient of the envelope is another poor person, as is his grandfather. Finally, we run a treatment in which rich and poor participants are asked to return an envelope via post as part of a purposefully banal research study, and thus returns are not reflective of pro-social concerns.

The rest of this paper is organized as follows. First, section 2 discusses related studies exploring the relation between wealth and pro-sociality. Section 3 then presents the experimental design and the procedure of identifying rich and poor households to include in our sample. In section 4 we present the main results from the experiment. Section 5 presents the

\footnotetext{
${ }^{8}$ While the latter suggests the likelihood of observing a statistically significant difference may be maximized when comparing the rich with the poor, evidence from charitable giving suggests otherwise. In particular, there is evidence of a U-shaped relation between income and giving, with the poorest households giving the most as a proportion of their income, followed by the richest households (Andreoni, 2006). Households in the middle give the least. Of course, giving in proportion of one's income is not the only metric. According to US data (Andreoni, 2015), in recent years, only 30 percent of households with annual incomes under $\$ 15,000$ gave to charity, while 91 percent of those earning above $\$ 200,000$ do. Conditional on giving, however, the lower income group gives 3.6 percent of income while the higher group gives 1.8 percent. Thus, taking all the evidence together, it is not obvious that by comparing the rich to the poor we are biasing our analysis either against or in favor of the rich.
} 
structural model. Section 6 explores alternative explanations for the low return rates of the poor. Lastly, section 7 concludes.

\section{Related literature}

In the aftermath of the financial crisis of 2008, the relationship between wealth and prosociality has been the focus of several empirical studies. Wealth and income are key determinants of "social class" along with education and occupational prestige. The first studies to explore the relationship between social class and pro-social (ethical) behavior documented a strong negative relationship: upper-class subjects in these studies, on average, gave smaller amounts in laboratory dictator and trust games than lower-class subjects; were less compassionate and believed people should give less to charity (Piff et al., 2010); had favorable attitudes towards greed and lied more (Piff et al., 2012); cheated more (Piff et al., 2012; Dubois et al., 2015); and were also less likely to help others (Piff et al., 2010; Guinote et al., 2015). These findings have attracted considerable attention by academics and media alike (e.g. Economist, 2010; Warner, 2010; Kraus et al., 2012; Hooker, 2015), although some have questioned their external validity on several grounds (e.g. Frank, 2011; Francis, 2012; Trautman et al., 2013; Korndörfer et al., 2015). One criticism is that these studies rely on small, convenience samples consisting predominantly of students. Due to the lack of variation in social class, these studies often use priming tasks to induce a subjective perception of class.

A different approach was followed by Trautman et al. (2013) and Korndörfer et al. (2015) who used representative survey panels and objective measures of social class. Using mostly German and US survey panels, Korndörfer et al. (2015) find an overall positive relationship between social class and charitable giving, volunteering, trusting and helping. Using a representative sample of the Dutch population, Trautman et al. (2013) are able to unpack the different components of "social class." 9 They find mixed results. For example, wealth is positively correlated with cheating on taxes and committing adultery, but also with volunteering and trusting others. Wealth is not correlated with lying, stealing, or accepting bribes. These findings cast doubt over the generalizability of the claims of Piff et al. (2010, 2012); Dubois et al. (2015) and Guinote et al. (2015). However, a limitation of the studies by Trautman et al. (2013) and Korndörfer et al. (2015) is that unethical behavior is self-reported. Given the topic, this is clearly problematic as a greater frequency of (self-reported) unethical behavior may reflect a lack of regard for others, but it also reflects the respondent's honesty, which is obviously related to the ethical behavior that is being studied.

\footnotetext{
${ }^{9}$ Another study conducted in the Netherlands is that by Volker et al. (2015). They drop letters on streets and observe whether they are returned. Volker et al. (2015) find a positive correlation between neighborhood wealth and return rates. An advantage of this method is that, as in our experiment, the authors observe actual pro-social behavior, but the interpretation of the data is unclear. First, it is uncertain who returns the lost letter. Second, wealth is very likely correlated with the quality of the social environment, which is known to affect pro-social behavior (Keizer et al., 2008).
} 
The aforementioned studies investigate whether rich individuals behave more selfishly. However, we believe that the important economic question is whether the rich and the poor have different pro-social attitudes, not simply different pro-social behaviors. This requires that the issue of endogeneity is addressed by paying attention to factors related to wealth that may affect behaviors, but not pro-social attitudes. To that end, our study is informed by and contributes to recent literature examining the negative effects of poverty on individual decision making (Shah et al., 2012; Mani et al., 2013; Mullainathan and Shafir, 2013; Carvalho et al., 2016). The evidence suggests that poverty entails a personal stress that those who are not poor do not also suffer from. This stress reduces the ability of the poor to deal with everyday tasks, and set priorities optimally (Mani et al., 2013; Haushofer and Fehr, 2014). In addition, evidence suggests that the poor may have difficulty saving (Karlan et al., 2014), and have a greater propensity to engage in impulse buying (Wood, 1998), all of which may partially be a consequence of this stress. Our findings suggest that financial stress can also crowd out pro-social behavior. Therefore, these results suggest a mechanism through which poverty may undermine social welfare more broadly.

\section{The experiment}

We begin by presenting the experimental design in section 3.1 and proceed to describe the process used for selecting households in section 3.2. In section 3.3 we show that the randomization of households into treatments was successful. Finally, in section 3.4 we discuss findings from an essential pre-test of the mail company.
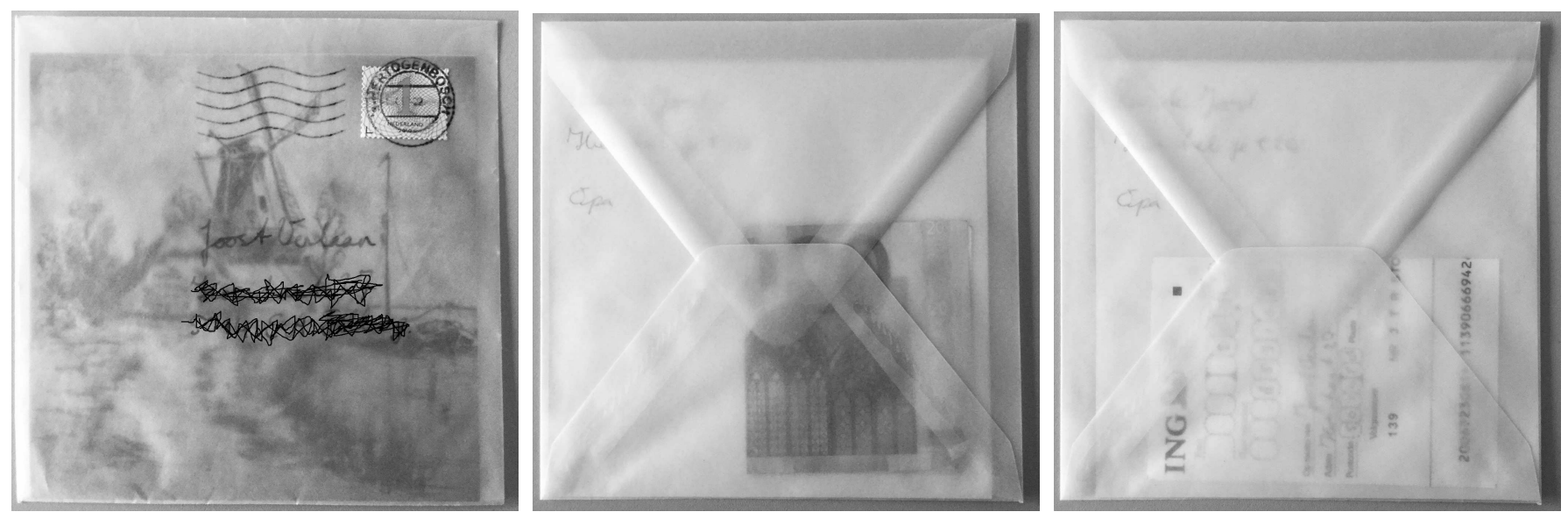

Figure 1 The envelopes in the experiment. 


\subsection{Experimental treatments and procedures}

In all treatments, a semi-transparent envelope was misdelivered in the mailbox of each preidentified household. All envelopes included an identical greeting card with the following message written on the back:

"Dear Joost, here is €x for you. -Grandfather."10

The message to Joost was clearly visible from the back side of the envelope, as can be seen in Figure 1, and hand-written for maximum authenticity. Joost is a real person, a research associate of ours, living in a middle-class neighborhood. ${ }^{11}$ His address was hand-written clearly on the front side of the envelope which also contained a stamp and a post-mark. ${ }^{12}$ The latter made it seem as if the envelope had been misdelivered by the mail company, when in fact it was (mis)delivered by us.

Table 1 Overview of the main treatments

\begin{tabular}{llc}
\hline Treatment & Content of Envelope & No of observations \\
\hline BTC5 & Bank transfer card of $€ 5$ & 90 (45 rich, 45 poor $)$ \\
BTC20 & Bank transfer card of $€ 20$ & 90 (45 rich, 45 poor $)$ \\
E5 & Bank note of $€ 5$ & 90 (45 rich, 45 poor $)$ \\
E20 & Bank note of $€ 20$ & 90 (45 rich, 45 poor $)$ \\
\hline
\end{tabular}

A returned envelope is a pro-social/altruistic act as the action benefits Joost. To have a better understanding of what motivates returns, we vary the contents of the envelopes across treatments. Table 1 provides an overview of our experimental treatments. As can be seen, in two treatments (BTC5, BTC20), in addition to the greeting card, we included a bank transfer card for the amount of $€ 5$, or $€ 20$. A bank transfer card is an order to transfer money from one bank account to another. It has no value for a third party, and it is impossible to go to a bank office to cash it. Therefore, there is no monetary gain from keeping an envelope with a bank transfer card. In the other two treatments (E5, E20), instead of bank transfer cards, a bank note of either $€ 5$ or $€ 20$ was included.

All treatments were conducted from early October to mid-December 2013. Letters were "misdelivered" on weekdays, between 1.00 p.m. and 2.00 p.m.; i.e., the same time the mail company makes deliveries. To avoid suspicion, misdeliveries were always done in the uniform of the official mail company. To control for day-of-the-week and week-of-the-year effects, we misdelivered an equal number of envelopes for each treatment each time a round of misdeliveries was done. (There were seventeen rounds in total.) We are able to keep track of which

\footnotetext{
${ }^{10}$ The untranslated Dutch text is: "Beste Joost, hier heb je €x. - Opa".

${ }^{11}$ We chose a middle-class neighborhood to avoid ingroup/outgroup effects between rich and poor. Later in the paper, we present evidence from a treatment in which the message on the card reveals that Joost and his grandfather are poor, and show that this does not affect our conclusions.

${ }^{12}$ Figure 1 omits this information for privacy reasons.
} 
household returned the envelope by noting the serial number of the bank notes, and by filling in different bank account numbers on the bank transfer cards before "misdelivering" the envelopes.

\subsection{Selecting poor and rich households}

Each household in our sample was randomly assigned to one of the four experimental treatments. Ideally, the selection of households would be based on their wealth. However, due to (understandable) security and privacy concerns, CBS Netherlands was unable to provide us with a list of households with their addresses and financial information in advance. They did agree to provide us with household-level data on wealth, income, and other socio-economic variables after data collection was completed. As a result, we needed to select poor and rich households based on a measure other than wealth, but highly correlated with it. Our selection was based on the value of the houses of the rich, and the rental prices of the houses of the poor. This section provides a brief summary on how this was done. Detailed information can be found in our Online Supplementary Material.

Addresses of poor households were acquired by collaborating with one of the city's social housing corporations. This corporation explicitly rents apartments in apartment blocks to the poorest people in the city and provided us with a list of their cheapest rental apartments. This list was not large enough to cover our sampling needs for two reasons. First, we wished to limit the number of households per apartment block to avoid contagion effects. Second, since rich households were anticipated to be (and indeed were) predominantly of Dutch origin, we intended to select only Dutch households for the poor too. For this reason, in addition to the list given by the social housing corporation, we also selected subjects renting apartments in buildings advertised on the corporations' website.

Addresses of rich households were acquired using www.Funda.nl, a Dutch website advertising houses for sale. We searched for houses advertised for $€ 750,000$ and above. We did not include these houses in our sample as they had a high likelihood of being vacant. With the aid of another website, www.Postcode.nl, we identified similar houses on the same streets. Again, we avoided selecting multiple nearby houses for fear of contagion effects. These restrictions limit the number of observations we can obtain per treatment, and indeed the number of treatments we could run. This implies that, in some instances, our tests may be under-

powered and our ability to structurally identify parameters is limited. This, however, seems almost unavoidable given the nature of our topic.

\subsection{Randomization}

Using the data obtained from CBS Netherlands, we can evaluate whether the randomization of households into treatments was successful. This is essential in order to be able to safely 
interpret the findings from the experiment. Table 2 reports by treatment the means of the variables that we collected and will use later on to establish the robustness of our findings.

The variable 'HH Age' in Table 2 is the average age of all adults in a household. 'Benefits' is a dummy with value one if at least one adult member of the household receives unemployment benefits, social welfare, social security, or disability insurance. 'HH Size' presents the average number of persons in a household, including children. 'Pension' is a dummy with value one if at least one adult member of the household receives pension. 'HH Foreign' is a dummy with value one if all adult members of a household are non-Dutch. 'Distance to Joost' and 'Distance to mailbox' measure the distance in kilometers from a house in our sample to Joost's house and the nearest mailbox, respectively. Finally, 'Density' is the ratio of houses in a street participating in our experiment over the total houses in a street. A greater ratio could indicate a greater probability of subjects communicating about the envelopes. Precise details on how (yearly) disposable income and wealth are calculated can be found in the Supplementary Material.

Table 2 Observable characteristics of rich and poor households; entries are means

\begin{tabular}{|c|c|c|c|c|c|c|c|c|c|c|}
\hline \multirow[b]{2}{*}{ Treatment } & \multicolumn{10}{|c|}{ The Rich } \\
\hline & $\begin{array}{l}\text { Disposable } \\
\text { Income }\end{array}$ & Wealth & $\begin{array}{l}\mathrm{HH} \\
\text { Age }\end{array}$ & $\begin{array}{l}\text { Bene- } \\
\text { fits }\end{array}$ & $\begin{array}{l}\mathrm{HH} \\
\text { Size }\end{array}$ & Pension & $\begin{array}{c}\mathrm{HH} \\
\text { Foreign }\end{array}$ & $\begin{array}{l}\text { Distance } \\
\text { Joost }\end{array}$ & $\begin{array}{l}\text { Distance } \\
\text { Mailbox }\end{array}$ & Density \\
\hline BTC5 & 87,641 & $3,451,325$ & 55.63 & 0.04 & 2.76 & 0.47 & 0.00 & 4.13 & 0.32 & 0.44 \\
\hline BTC20 & 87,312 & $1,689,802$ & 56.73 & 0.13 & 2.8 & 0.40 & 0.00 & 3.95 & 0.37 & 0.43 \\
\hline E5 & 84,616 & $2,749,497$ & 56.81 & 0.07 & 2.73 & 0.44 & 0.00 & 4.16 & 0.35 & 0.41 \\
\hline E20 & 78,587 & $2,095,890$ & 56.57 & 0.07 & 2.78 & 0.40 & 0.00 & 4.39 & 0.35 & 0.42 \\
\hline Average & 84,539 & $2,496,629$ & 56.44 & 0.08 & 2.77 & 0.43 & 0.00 & 4.16 & 0.35 & 0.43 \\
\hline Treatment & $\begin{array}{c}\text { Disposable } \\
\text { Income }\end{array}$ & Wealth & $\begin{array}{l}\mathrm{HH} \\
\text { Age }\end{array}$ & $\begin{array}{l}\text { Bene- } \\
\text { fits }\end{array}$ & $\begin{array}{c}{ }^{7} \\
\mathrm{HH} \\
\text { Size }\end{array}$ & $\begin{array}{l}\text { e Poor } \\
\text { Pension }\end{array}$ & $\begin{array}{c}\mathrm{HH} \\
\text { Foreign }\end{array}$ & $\begin{array}{c}\text { Distance } \\
\text { Joost }\end{array}$ & $\begin{array}{l}\text { Distance } \\
\text { Mailbox }\end{array}$ & Density \\
\hline BTC5 & 19,208 & 26,320 & 42.23 & 0.31 & 1.33 & 0.11 & 0.13 & 3.55 & 0.24 & 0.35 \\
\hline BTC20 & 18,924 & 15,655 & 45.41 & 0.31 & 1.53 & 0.20 & 0.18 & 3.53 & 0.25 & 0.35 \\
\hline E5 & 20,689 & 53,747 & 43.29 & 0.31 & 1.4 & 0.18 & 0.13 & 3.52 & 0.25 & 0.35 \\
\hline $\mathrm{E} 20$ & 17,276 & 13,223 & 38.88 & 0.4 & 1.47 & 0.07 & 0.16 & 3.52 & 0.25 & 0.35 \\
\hline Average & 19,024 & 27,236 & 42.45 & 0.33 & 1.43 & 0.14 & 0.15 & 3.53 & 0.25 & 0.35 \\
\hline
\end{tabular}

The randomization into treatments appears to have been successful. Using Kruskal-Wallis tests, we cannot reject the hypothesis of an equal distribution of disposable income among the rich $\left(p=0.92, N_{1}=43, N_{2}=45, N_{3}=43, N_{4}=40\right)$ and among the poor $\left(p=0.14, N_{1}=\right.$ $\left.44, N_{2}=44, N_{3}=43, N_{4}=45\right) .{ }^{13}$ The same holds for wealth for the rich $(p=0.51)$ and for wealth of the poor $(p=0.16)$. A similar analysis is done for all other variables in Table 2, using Fisher Exact tests for dummy variables. All $p$-values are 0.21 or greater. Table 2 shows that the rich differ from the poor in more than just disposable income and wealth. The rich, on average, are: older, live further from Joost and the nearest mailbox, have larger families,

\footnotetext{
${ }^{13}$ The number of observations per treatment was 45 in all cases. CBS Netherlands was unable to provide us with information on certain variables in a small number of cases, as noted.
} 
are less ethnically diverse, receive more pensions, but fewer benefits. In contrast, we do not find a difference when we compare households for which at least one member receives either a pension or benefits (implying that at least one family member is likely to be at home). The share of such households is 0.49 for both groups.

\subsection{Testing the mailman}

The most cost-effective way to return a misdelivered envelope is to drop it into one of the public mail-boxes on the street. This procedure, however, adds noise to our data as an unreturned envelope could be either due to being kept by the household, or due to being kept by the mailman. To measure the amount of noise that mailmen add, we posted ourselves envelopes from all experimental treatments directly to the address of the recipient (Joost). Test envelopes were sent on the same days on which the experiment was conducted. Furthermore, these envelopes were mailed from the same neighborhoods as the houses in our sample.

In total, we posted 85 envelopes directly to Joost. Only one envelope out of 85 was not properly delivered to Joost. In fact, the envelope itself was delivered, but the bank note of $€ 20$ was missing. The return rate of $98.82 \%$ in this study corresponds to a similar test reported in Stoop (2014), showing a return rate of 98.56\%. Given these high return rates, we interpret return rates in the experiment as free from noise from the mail company.

\section{Experimental results}

In this section, we begin by comparing return rates across treatments for rich and poor. We then proceed to establish the robustness of our findings by controlling for a range of socio-economic variables at the household level.

Result 1: The rich return substantially more envelopes than the poor. Across treatments, they are more than twice as likely to return a misdelivered envelope (81 vs. 38 percent).

Support: Figure 2 shows the percentage of returned envelopes in each of the treatments. In all four treatments, the rich are considerably more likely to return misdelivered envelopes. Two-tailed Fisher-Exact tests reveal that the difference is statistically significant in all four cases $(p<0.01 ; N=90$ for each treatment).

Result 2: The poor are $41.85 \%$ less likely to return envelopes containing money than envelopes containing bank transfer cards. The rich are $10.39 \%$ less likely to return envelopes containing money than envelopes containing bank transfer cards. The difference is statistically significant for the poor, but not the rich.

Support: For the poor, the average return rate across non-cash (BTC5 and BTC20) and cash treatments (E5 and E20) is $47.78 \%$ and $27.78 \%$, respectively. The reduction of $41.85 \%$ is statistically significant (Fisher-Exact, $p<0.01, N=180$ ). Comparing rates in E20 and 


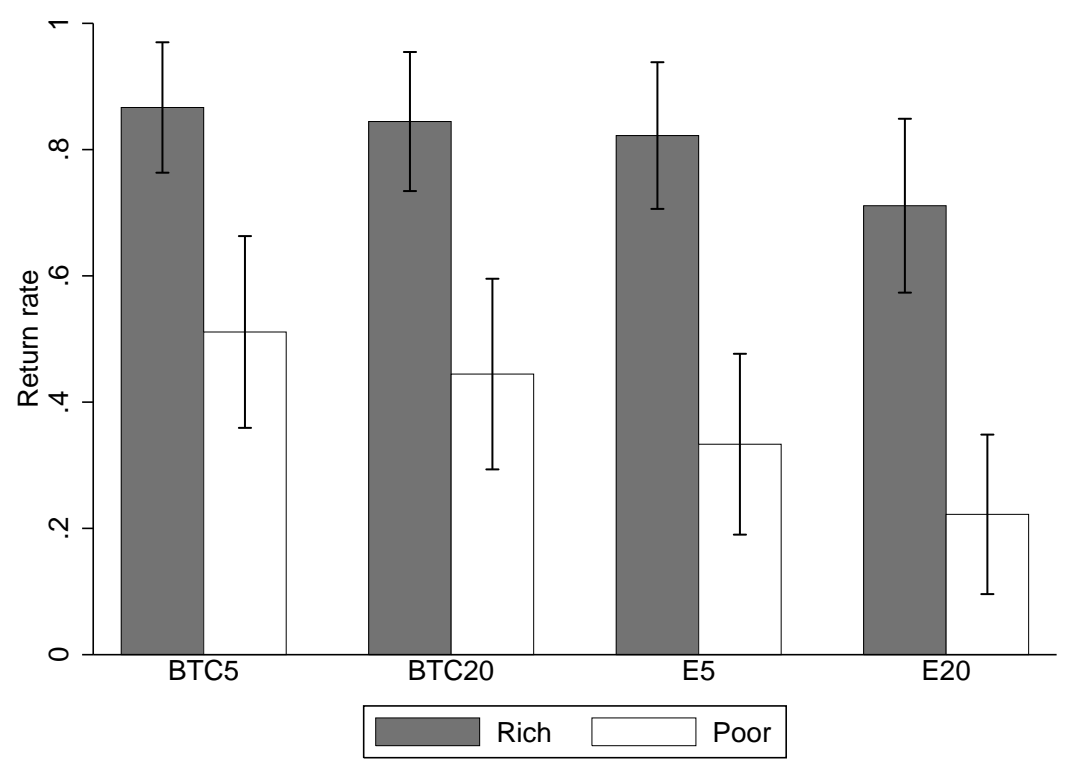

Figure 2 Percentage of envelopes returned ( $N=45$ in each treatment). BTC 5 (BTC 20) is the treatment that contains a bank transfer card of $€ 5(€ 20)$ per envelope. E5 (E20) is the treatment that contains $€ 5(€ 20)$ per envelope.

BTC20 for the poor, the difference is also statistically significant (Fisher-Exact, $p=0.04$, $N=90$ ). The $35 \%$ reduction in returns in E5 and BTC5 however is not, due to our modest sample size (Fisher-Exact, $p=0.14, N=90$ ). For the rich, the average return rate across non-cash treatments and cash treatments is $85.56 \%$ and $76.67 \%$, respectively. This amounts to a reduction of $10.39 \%$, a difference which, given our sample size, is not statistically significant (Fisher-Exact, $p=0.18, N=180$ ). Neither the difference between E5 and BTC5 (FisherExact, $p=0.77, N=90$ ) nor that between E20 and BTC20 (Fisher-Exact, $p=0.20, N=90$ ) is statistically significant.

Result 3: Return rates are sensitive neither to the amount of money in the envelopes nor to the amount on the bank transfer cards.

Support: For the rich, the return rate decreases insignificantly from $87 \%$ in BTC5 to $84 \%$ in BTC20 (Fisher-Exact, $p=1.00, N=90$ ). For the poor, the return rate decreases from $51 \%$ in BTC5 to $44 \%$ in BTC20, but the difference is again insignificant (Fisher-Exact, $p=0.67$, $N=90$ ). This finding suggests that the decision to return the envelope is not driven by altruistic concerns for the welfare of Joost. The difference in return rates between E5 and E20 is insignificant both for the rich (Fisher-Exact, $p=0.32, N=90$ ) and the poor (FisherExact, $p=0.35, N=90)$.

Next, we use the household-level data obtained from CBS Netherlands and other observable variables we collected to check for the robustness of our results in a regression analysis. 
The dependent variable is binary, taking the value 1 when a household returned the envelope, and 0 otherwise. Table 3 shows the marginal effects from a series of Probit regressions. Models (i)-(iii) include dummies for our main experimental treatments. For brevity, we include one dummy for the two cash treatments (E5, E20) and one for the two non-cash treatments (BTC5, BTC20). Model (iv) adds variables related to our household selection: 'Distance to Joost', 'Distance to Mailbox', and 'Density'. Model (v) adds 'HH Foreign', 'Benefits', 'Pension', 'HH Size' and 'HH Age', but excludes the dummies for household selection. Models (vi) and (vii) include all variables, with the latter clustering the standard errors at the street level.

Table 3 The determinants of returning envelopes

\begin{tabular}{|c|c|c|c|c|c|c|c|}
\hline & (i) & (ii) & (iii) & (iv) & $(\mathrm{v})$ & (vi) & (vii) \\
\hline Rich & $\begin{array}{c}0.43^{* * *} \\
(0.05)\end{array}$ & $\begin{array}{c}0.44^{* * *} \\
(0.05)\end{array}$ & $\begin{array}{c}0.41^{* * *} \\
(0.07)\end{array}$ & $\begin{array}{c}0.44^{* * *} \\
(0.07)\end{array}$ & $\begin{array}{c}0.35^{* * *} \\
(0.09)\end{array}$ & $\begin{array}{c}0.38^{* * *} \\
(0.09)\end{array}$ & $\begin{array}{c}0.38^{* * *} \\
(0.08)\end{array}$ \\
\hline Cash & & $\begin{array}{c}-0.17^{* * *} \\
(0.05)\end{array}$ & $\begin{array}{c}-0.20^{* * *} \\
(0.07)\end{array}$ & $\begin{array}{c}-0.20^{* * *} \\
(0.07)\end{array}$ & $\begin{array}{c}-0.20^{* * *} \\
(0.07)\end{array}$ & $\begin{array}{c}-0.20^{* * *} \\
(0.07)\end{array}$ & $\begin{array}{c}-0.20^{* *} \\
(0.08)\end{array}$ \\
\hline Rich $\times$ Cash & & & $\begin{array}{c}0.08 \\
(0.11)\end{array}$ & $\begin{array}{c}0.08 \\
(0.11)\end{array}$ & $\begin{array}{c}0.07 \\
(0.11)\end{array}$ & $\begin{array}{c}0.07 \\
(0.11)\end{array}$ & $\begin{array}{l}0.07 \\
(0.1)\end{array}$ \\
\hline Dist. Joost & & & & $\begin{array}{l}-0.02 \\
(0.02)\end{array}$ & & $\begin{array}{l}-0.02 \\
(0.02)\end{array}$ & $\begin{array}{c}-0.02 \\
(0.01)\end{array}$ \\
\hline Dist. Mailbox & & & & $\begin{array}{l}-0.20 \\
(0.12)\end{array}$ & & $\begin{array}{l}-0.20 \\
(0.12)\end{array}$ & $\begin{array}{c}-0.20^{* * *} \\
(0.08)\end{array}$ \\
\hline Density & & & & $\begin{array}{l}-0.08 \\
(0.25)\end{array}$ & & $\begin{array}{l}-0.05 \\
(0.25)\end{array}$ & $\begin{array}{c}-0.05 \\
(0.2)\end{array}$ \\
\hline HH Foreign & & & & & $\begin{array}{l}-0.11 \\
(0.11)\end{array}$ & $\begin{array}{l}-0.11 \\
(0.11)\end{array}$ & $\begin{array}{c}-0.11 \\
(0.1)\end{array}$ \\
\hline Benefits & & & & & $\begin{array}{l}-0.01 \\
(0.07)\end{array}$ & $\begin{array}{l}-0.02 \\
(0.07)\end{array}$ & $\begin{array}{l}-0.02 \\
(0.07)\end{array}$ \\
\hline Pension & & & & & $\begin{array}{l}-0.02 \\
(0.09)\end{array}$ & $\begin{array}{l}-0.03 \\
(0.09)\end{array}$ & $\begin{array}{l}-0.03 \\
(0.11)\end{array}$ \\
\hline HH Size & & & & & $\begin{array}{c}0.01 \\
(0.03)\end{array}$ & $\begin{array}{c}0.01 \\
(0.03)\end{array}$ & $\begin{array}{c}0.01 \\
(0.03)\end{array}$ \\
\hline HH Age & & & & & $\begin{array}{c}0.00 \\
(0.00)\end{array}$ & $\begin{array}{c}0.00 \\
(0.00)\end{array}$ & $\begin{array}{c}0.00 \\
(0.00)\end{array}$ \\
\hline$N$ & 360 & 360 & 360 & 360 & 360 & 360 & 360 \\
\hline Pseudo $R^{2}$ & 0.15 & 0.17 & 0.17 & 0.18 & 0.18 & 0.18 & 0.18 \\
\hline
\end{tabular}

Coefficients are marginal effects following Probit regressions.

The dependent variable has a value of 1 when a household returns the envelope and 0 otherwise.

Standard errors are shown in parentheses. In the last column, standard errors are clustered at the street level. $*^{* * *},{ }^{* *},{ }^{*}$ : significant at the $0.01,0.05,0.10$ levels, respectively.

The estimates show that our conclusions are unaffected when we control for these observable characteristics. In particular, we find that rich households return significantly more envelopes, even when controlling for ethnic background, receiving pension or government 
benefits, household size, and household age. ${ }^{14}$ The magnitude of 'Rich' decreases slightly as more controls are added, but it always remains significantly positive. In contrast, the effects of the control variables are relatively small and, with one exception, always statistically insignificant. The interaction term 'Rich $\times$ Cash' shows that relative to non-cash envelopes, the rich are 7 to 8 percentage points more likely to return cash envelopes than the poor are (i.e., this is a diff-in-diff comparison). As we saw above, the relative difference for rich and poor is substantial (10.39\% for the rich vs. $41.85 \%$ for the poor). But the absolute difference is smaller ( $8.89 \%$ for the rich vs. $20.00 \%$ for the poor) and our sample is not large enough to provide us with a powerful test. Finally, the distance to a mailbox is the only other variable that is significant in the last model (and borderline insignificant in the other models). Although a Type I error is possible, the variable suggests that subjects are less likely to return an envelope when the costs of doing so are greater. ${ }^{15}$

The next section combines the data from all the treatments in a simple model which we structurally estimate. The goal is to obtain a deeper understanding of the underlying differences between rich and poor.

\section{Estimation based on a simple theory of motivation}

Observing a difference in return rates between rich and poor, although informative, does not by itself suffice to establish the reasons underlying this difference. Differences in return rates could be due to differences in pro-social preferences, but they could also be due to other kinds of differences associated with wealth. In this section, we present a simple model to better understand the underlying motives of rich and poor for returning envelopes in the experiment. By necessity, the model is sparsely parametrized as, with only four treatments, we can only identify few parameters. As a consequence, the objective of this exercise is not to precisely identify the objectives of rich and poor in our sample (e.g., altruism, morality, warm-glow), but to gain a sense of how much the poor and rich differ in their basic pro-sociality, if at all. For simplicity, in what follows, we will use the term "altruism" to refer generally to the

\footnotetext{
${ }^{14}$ One possible concern with our experiment could be that it is not the rich who return the envelopes, but rather staff working for them. This assumes that the staff has access to the private mailbox of the household, which is not necessary given that mailboxes often require keys. It also assumes that the staff, which presumably is not rich, prefers to return the envelope rather than keep it for them. Nevertheless, to explore whether there is some validity in this concern we estimated the models in Table 3 using only unemployed individuals and pensioners. Only 169 households consist exclusively of such individuals which limits considerably our power to detect any differences. Our main findings are, however, both qualitatively and quantitatively unaffected.

${ }^{15}$ We were also interested to explore the mediating effect of education on the willingness of rich to return envelopes. Unfortunately, CBS Netherlands could provide us this information for only a third of our sample. We distinguish between three levels of education. In increasing level, the poor return 42 percent, 54 percent and 86 percent $(N=36+24+14=74)$. The corresponding return rates for the rich are 77 percent, 86 percent, and 88 percent $(N=26+7+26)$. Since we do not know the cause of the missing observations on education interpreting this data is problematic. All they can say is that, since the rich return more envelopes for low and medium levels of education, the data suggests education cannot fully account for the higher willingness of the rich to return letters.
} 
different reasons for which a person may feel inclined to return an envelope.

We start by asking ourselves: in what fundamental ways could wealth affect return rates? First, intuitively, a primary motive when deciding to return an envelope belonging to someone else is likely to be a concern for others. One possibility is that these "altruistic" concerns are luxuries of a sort - affordable only after a person's own basic needs have been met - and so may carry less weight for the poor than for the rich. On the other hand, if the poor are more empathic and compassionate than the rich because of their life experiences (Kraus et al., 2012), these concerns may have a greater weight for the poor. Second, poverty has been associated with stress and negative affective states which can change people's behaviorally revealed (risk and time) preferences (e.g. Haushofer and Fehr, 2014). Furthermore, it has been shown that financial pressure can affect one's priorities and ability to exert cognitive control. ${ }^{16}$ In the context of our study, this could imply that the willingness of the poor to return envelopes changes over the course of a month. Near the end of the month, when financial pressure peaks, the tasks deemed most inessential may be neglected in favor of those regarded as essential. Doing a favor for a stranger may be a task whose priority falls as the distance from payday increases, especially if that favor yields small benefits for the stranger.

Consider the different motives for returning envelopes in our treatments. The only benefit to the false recipient from not returning the envelopes without cash (the BTC conditions) is saving the effort of one more chore The benefit to Joost from returning the envelope rather than keeping it may also be regarded as small-once he and his grandfather realize the envelope was lost, they can issue a new BTC without any actual monetary loss. In contrast, in the treatments in which the envelopes contained cash, failure to return envelopes has real consequences - moral and economic - for both the false recipient and Joost. Therefore, all else equal, we would expect that poor people would be less likely to ignore the envelopes containing cash. This of course does not imply that they would be more likely to return envelopes containing cash, since there is a personal monetary benefit from retaining them. ${ }^{17}$

We can test these ideas in our data. Those in our sample on public assistance are paid either on the 22nd or 23rd day of each month. While we do not know exactly when the wealthy are paid their salaries, it is common in the Netherlands for pensions and monthly paychecks to be received around these same dates. As a first look for such an effect, Figure 3 presents the return rates for each week within a (salary) month, where week 0 indicates the week immediately after payment.

An interesting pattern emerges in Figure 3. For the poor, a peak in return rates of

\footnotetext{
${ }^{16}$ For instance, Mani et al. (2013) found that, in contrast to rich individuals, poor people performed worse on tasks measuring cognitive control and intelligence after they had been made to think about their finances. Similarly, they found that farmers performed worse shortly before the harvest, when they were relatively poor, than after it, suggesting poverty may change one's allocation of attention.

${ }^{17}$ One could imagine a person first deciding whether to keep or return an envelope with cash. If they decide to return it, then the envelope has properties similar to the BTC envelopes, making those cash envelopes intended for return subject to the pressure that mounts over the course of a month.
} 

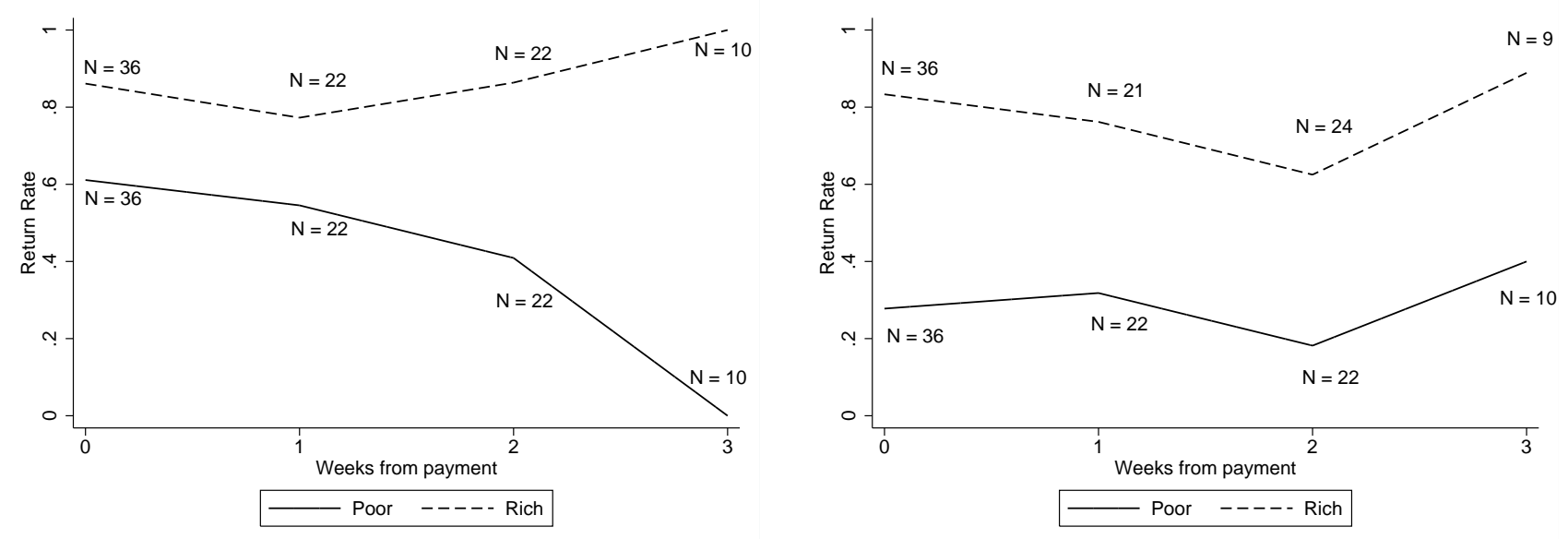

Figure 3 Return rates over the month of: (left panel) non-cash envelopes, (right panel) cash envelopes.

envelopes in BTC5 and BTC20 is found in the week of payment. Return rates decline significantly as the weeks go by (Pearson, $\rho=-0.93, p=0.07$; Spearman, $\rho=-1.00, p<0.01$ ). Looking at the right panel, we see no declining rates of return for the poor in treatments E5 and E20 for the poor (Pearson, $\rho=0.33, p=0.67$; Spearman, $\rho=0.4, p=0.60$. Taken together, these patterns suggest the poor regard the return of BTC envelopes as of lower priority than the return of envelopes containing cash. This is consistent with the hypothesis that financial pressure peaks just before one is paid which can affect one's priorities.

\subsection{A simple model}

For brevity and ease of presentation, we will combine the BTC5 and BTC20 conditions into a single condition called BTC and indexed by $b$. Likewise, the Euro 5 and Euro 20 conditions will be combined to form a single condition called Euro and indexed by $€$. Nearly identical results come when the two conditions are separated by the $€ 5$ and $€ 20$ conditions, treated separately for both BTC and Euros. This analysis is shown in the Online Supplementary Material.

Let $\alpha$ represent the altruistic propensity to return an envelope of value to another. To reflect the effects of financial pressure on the ability to achieve small tasks, let $w$ stand for the weeks from the pay-week, $w \in\{0,1,2,3\}$, so that $w=0$ is pay-week and $w=3$ is the week just prior to the pay-week. Let $P(w, k)$ indicate the effects of financial pressure on the fundamental propensity to return the envelope in condition $k \in\{b, €\}$ and week $w$. Assume the effect of pressure is linear in $w$, and can be written $P(w, k)=p_{0, k}+p_{k}(w+1)=p_{0, k}+p_{k}+p_{k} w$ for $w \in\{0,1,2,3\} .18$ Thus, pressure is the highest in week 3 , equaling $p_{0, k}+4 p_{k}$, but pressure

\footnotetext{
${ }^{18}$ The assumption of linearity simplifies our discussion, but it is not critical for our findings. We reach the same conclusions when we estimate our model using different specifications, such as including week dummies.
} 
from being poor does not disappear entirely during the week the paycheck is received. In week 0 , the week payments arrive, pressure is still positive at $p_{0, k}+p_{k}$.

Notice that this formulation assumes that the marginal effect of going from week 1 to week 0 is the same as from going from week 3 to week 2 . That is, pressure falls by $p_{k}$. However, there may be some residual pressure still felt in week 0 , especially for the poor. Therefore, we would expect $p_{0, k} \geq 0$. Unfortunately, our analysis does not allow for the identification of $p_{0, k}$. We will therefore assume that $p_{0, k}=0$. This assumption is conservative in the sense that, if the residual pressure in week 0 is indeed higher for the poor, then we would be underestimating their pro-social tendencies.

An individual in the BTC condition will return the envelope in week $w$ when the benefit obtained from doing so exceeds the negative effect of the pressure she experiences, that is, if

$$
\alpha-p_{b}(w+1)=\alpha-p_{b}-p_{b} w>0 \text { for } w \in\{0,1,2,3\} .
$$

For the Euro conditions, we can assume the net benefits of returning the envelopes are as in (1). However, keeping the cash envelopes has the benefit of the additional money, but a potential moral cost (such as feelings of guilt). Let $n$ denote the net benefit from keeping the envelopes containing cash. Even if the rich and the poor feel equally guilty for keeping the envelopes, if the marginal utility of money is higher for the poor, then we could expect these values to be higher for the poor than for the rich. Overall, envelopes will be returned in the Euro condition if

$$
\alpha-n-p_{€}-p_{€} w>0 .
$$

\subsection{Estimating the model}

We estimate the parameters of our model using a simple Probit regression of the return rates in our experiment. The explanatory variables include a dummy taking the value of 1 if the observation comes from a BTC treatment, a dummy taking the value of 1 if the observations comes from a Euro treatment, and interaction terms of these dummies with $w$, which equals the number of weeks from the pay-week.

Table 4 presents the estimates from the Probit regressions. The model is estimated without a constant, meaning that an insignificant coefficient implies that we cannot reject the hypothesis that the probability of an envelope being returned in a given treatment is $50 \%$; a coefficient of $1(-1)$ implies that the probability is roughly $66 \%(34 \%)$, and a coefficient of $1.96(-1.96)$ a probability of $95 \%(5 \%)$. Columns (1), (2), and (3) in Table 4 are a restatement of our main results, with the rich being significantly more likely to return the envelopes in each condition. Columns (4), (5), and (6) add the two interaction terms: $w \times B T C$ and $w \times$ Euro. $^{19}$

\footnotetext{
${ }^{19}$ The fact that our regression analysis allows for different coefficients on weeks, $w$, for the BTC and Euro
} 
Table 4 Probit estimates of return rates in the experiment.

\begin{tabular}{lcccccc}
\hline & $(1)$ & $(2)$ & $(3)$ & $(4)$ & $(5)$ & $(6)$ \\
Variable & Rich & Poor & Difference & Rich & Poor & Difference \\
\hline BTC $\left(\beta_{b}\right)$ & $1.061^{* * *}$ & -0.056 & $1.116^{* * *}$ & $0.919^{* * *}$ & $0.403^{* *}$ & $0.516^{* *}$ \\
& $(0.134)$ & $(0.151)$ & $(0.199)$ & $(0.172)$ & $(0.193)$ & $(0.255)$ \\
Euro $\left(\beta_{€}\right)$ & $0.728^{* * *}$ & $-0.589^{* * *}$ & $1.317^{* * *}$ & $0.868^{* * *}$ & $-0.600^{* * *}$ & $1.468^{* * *}$ \\
& $(0.118)$ & $(0.116)$ & $(0.163)$ & $(0.099)$ & $(0.178)$ & $(0.200)$ \\
$w \times$ BTC $\left(\beta_{b, w}\right)$ & & & & 0.144 & $-0.447^{* * *}$ & $0.591^{* * *}$ \\
& & & & $(0.117)$ & $(0.121)$ & $(0.166)$ \\
$w \times$ Euro $\left(\beta_{€, w}\right)$ & & & & -0.125 & 0.010 & -0.135 \\
& 180 & 180 & 360 & 180 & 180 & 360 \\
\hline$N$ & & & & $(0.112)$ & $(0.169)$ & $(0.199)$ \\
\hline
\end{tabular}

The dependent variable has a value of 1 when a household returns the envelope.

Standard errors are clustered at the street level.

***, ${ }^{* *},{ }^{*}$ : significant at the $0.01,0.05,0.10$ levels, respectively.

As expected, the coefficient for the poor in the BTC conditions are significant, and more negative than those in the Euro condition. However, including these variables in the estimation has a pronounced effect on the coefficients on BTC. As can be seen in column (3), the coefficients for the rich and poor in BTC are now much closer to each other than they were previously. In contrast, in the Euro conditions, the coefficients remain roughly equally apart.

Next, we interpret the coefficients in columns (4) and (5) using our simple model. From equation (1), we see that $\beta_{b}=\alpha-p_{b}$ and $\beta_{b, w}=-p_{b}$. Thus we can calculate $\alpha$ as $\alpha=\beta_{b}+p_{b}=$ $\beta_{b}-\beta_{b, w}$. Similarly, from equation (2), we see that $\beta_{€}=\alpha-n-p_{€}$ and $\beta_{€, w}=-p_{€}$. We can use the value of $\alpha$ calculated from the BTC equations to identify $n$ as $n=\beta_{b}-\beta_{b, w}+\beta_{€, w}-\beta_{€}$.

Table 5 presents the estimated coefficients for our simple model, using the coefficients from Table 4. As can be seen, when taking into consideration the effects of financial pressure, we estimate an $\alpha$ for the rich of 0.776 and for the poor of 0.850 . This difference is statistically insignificant. In other words, the structural model suggests that rich and poor do not differ in their "altruistic" concerns. Instead, the poor appear to experience substantial financial pressure causing them to return fewer BTC envelopes, especially just before their payday.

The model also suggests that the net utility of keeping the cash envelopes is very close to 0 for the rich, both in terms of statistical and economic significance. In contrast, the poor appear to derive positive net utility. The value of $n=1.461$ for the poor suggest a very high incentive to keep the cash envelopes regardless of the cognitive pressures of time, and is consistent with the near zero value for $-\beta_{€, w}$. Thus, either the poor feel little guilt from keeping the cash, or the marginal utility of money for the poor is significantly higher, or both.

conditions relates to our earlier discussion about the decision to keep or return an envelope with cash. For many of our subjects, it may be that the marginal utility of money is so high that $\alpha-n<0$ at the outset, and so any additional disincentive to return envelopes due to the congitive pressures of poverty will be irrelevant. For this reason we expect $\beta_{€, w}<\beta_{b, w}$. 
Table 5 Parameter values for the simple behavioral model set out in expressions (1) and (2).

\begin{tabular}{lccccc}
\hline & Variable & Formula & Rich & Poor & Difference \\
\hline Altruism : & $\alpha$ & $\beta_{b}-\beta_{b, w}$ & $0.776^{* * *}$ & $0.850^{* * *}$ & -0.075 \\
& & & $(0.256)$ & $(0.230)$ & $(0.380)$ \\
Net utility from & $n$ & $\beta_{b}-\beta_{b, w}+\beta_{€, w}-\beta_{€}$ & -0.218 & $1.461^{* * *}$ & $-1.678^{* * *}$ \\
keeping cash: & & & $(0.362)$ & $(0.379)$ & $(0.516)$ \\
Pressure: & $p_{b}$ & $-\beta_{b, w}$ & -0.144 & $0.447^{* * *}$ & $-0.591^{* * *}$ \\
& & & $(0.117)$ & $(0.121)$ & $(0.166)$ \\
& $p_{€}$ & $-\beta_{€, w}$ & 0.125 & -0.010 & 0.135 \\
& & & $(0.112)$ & $(0.169)$ & $(0.199)$ \\
\hline
\end{tabular}

Standard errors are in parentheses.

${ }^{* * *},{ }^{* *},{ }^{*}$ : significant at the $0.01,0.05,0.10$ levels, respectively.

Given the first result that the poor appear to be as altruistic as the rich, the more compelling interpretation is that they have greater need for money.

In the introduction, we argued that the evidence in myriad studies showing that the wealthy behave more selfishly than others could not support claims that they are more selfish, due to endogeneity problems. Our field experiment has provided evidence that, contrary to popular beliefs, the rich actually behave more pro-socially. The modeling exercise presented in this section has shown that, despite using a design aimed to minimize several of the common inference problems when dealing with the rich, endogeneity due to omitted variables remains an issue. Once we account for differences in the marginal utility of income and financial pressure, the rich and the poor appear to be indistinguishable with regards to their pro-social tendencies.

\section{Discussion of alternative explanations}

In this section, we consider alternative explanations for the observed differences between rich and poor. Specifically, we will explore three possible reasons for why the poor return relatively few envelopes, even when retaining them would not benefit them directly (i.e., in treatments BTC5, BTC20). Section 6.1 presents evidence from a survey exploring the poor's use of mail and their knowledge of returning misdelivered mail. In section 6.2 , we test the hypothesis that the poor are less likely to help Joost because he lives in a middle-class neighborhood. Finally, in 6.3, we present evidence from a treatment in which rich and poor participants are simply asked to return an envelope via post as part of a research study in exchange for $€ 20$. 


\subsection{Finding misdelivered envelopes and knowing how to return them}

One possible explanation for the lower return rates of the poor, especially for the BTC conditions, is that they check their mailboxes less frequently than the rich. Alternatively, it is possible that, even if they do check, they are not as knowledgeable as the rich on how to return them. To explore these explanations, we conducted a survey.

The survey was conducted in the same city where the experiment was run, outside the social housing corporation that helped us in identifying poor households. We approached people that walked by, and asked $(i)$ if the person had time to participate in a short survey, and if so, (ii) did they rent a house or apartment at a social housing corporation (as the poor in our sample do). Only if both answers were positive the survey was conducted. In total, between April and May of 2014, 45 individuals were surveyed of which 23 were female. The surveys took place on weekdays between 1:00 pm and 3:00 pm, and on average took five minutes to complete. The questionnaire and details on the procedure can be found in the Online Supplementary Material.

The results of the questionnaire show that, on average, respondents check their mailboxes six times per week. A total of 34 subjects (75.5\%) check their mailbox every day, while four subjects $(8.9 \%)$ check their mailbox at most twice per week. Further, when answering a question about how to return misdelivered mail, 89 percent of the subjects came up with the most cost-efficient solution: put the envelope in any of the mail company's public mailboxes on the street. While our survey questions were not incentivized, the high fraction of correct answers to this question also gives us greater confidence in the accuracy of prior responses, which we, of course, cannot verify for accuracy.

As a robustness check we reproduced the supporting analysis for Result 1, under the assumption that 100 percent of the rich know how to return a misdirected envelop and only 89 percent of the poor do. That is, we delete 11 percent of the poor households in each treatment that did not return envelopes, assuming that they did not know how to do so. All rich-poor comparisons still have $p$-values smaller than 0.01. Alternatively, we can determine how many of the poor households should be excluded from the sample to not be able to reject the null hypothesis of an equal distribution between rich and poor households (at the five percent level). Pooling all data, the data set of the poor should be reduced to 54 percent of our current database, keeping all households that return the envelope. Therefore, we are confident that the lower overall return rate of the poor cannot be explained by either a less frequent collection of their mail or a reduced understanding of how to return misdelivered envelopes.

\subsection{What if Joost was also poor?}

Although participants in the experiment did not know Joost personally, his address was in a middle-class neighborhood. Therefore, it is possible that Joost could be perceived differently 
by the poor and the rich: the poor could see Joost as someone better off, while the rich as someone worse off. This implies that one possible explanation for the differences in return rates between rich and poor is concerns for equality (e.g., Fehr and Schmidt, 1999). To test this explanation, we conducted a treatment similar to BTC20 in which we manipulated the message on the greeting card to reduce the perceived social distance between the recipient of the misdelivered envelope, the intended recipient (Joost), and also the sender (Grandfather). In this treatment, referred to as Poor Joost, we misdelivered transparent envelopes with a bank transfer card for the amount of $€ 20$. The text on the card read:

"Dear Joost, I understand you are still waiting for a social housing apartment to become available and you are having trouble paying your bills. Here is €20 for you. I know it's not much, but it is all I can afford. - Grandfather." 20

The Poor Joost treatment was conducted in September 2014 among poor households only. A total of 45 (new) poor households were selected from apartment buildings that appear on the website of the social housing corporation. Misdeliveries were done on weekdays between 1:00 p.m. and 2:00 p.m. in official corporate clothing of the mail company. We excluded rich households for two reasons. First, a recent paper by Bauer et al. (2015) shows that Dutch millionaires in a dictator game give more to non-millionaires than to fellow millionaires. If these results translate to behavior in the field (as we expect), the rich would be even more likely to help in "PoorJoost" than in our previous treatments. Second, as mentioned, there is a limited supply of rich households in the city where the experiments was conducted. The previous treatments described in section 3 used up almost all of the eligible rich households.

Since the Poor Joost treatment was run at a different time, we conducted another test of the efficiency of the mail company on the same days as the Poor Joost treatment. In total, 17 envelopes identical to those used in the Poor Joost treatments were mailed from mailboxes in the same neighborhoods. All of these envelopes arrived the day after sending them. We thus interpret the return rate in the Poor Joost treatment as being free from mail-company noise.

The rate of return in the PoorJoost treatment is equal to 0.53. Recall, that the average return rate for the BTC treatments was 0.47. A $2 \times 2$ Fisher Exact test cannot reject the null hypothesis of an equal return rate between Poor Joost and the two BTC treatments at any of the conventional levels of significance $(N=135, p=0.59)$. This is evidence that inequality concerns cannot explain our findings.

\subsection{The Private Incentives treatment}

Finally, we ran treatment Private Incentives (henceforth PI), in which "altruistic" concerns could not account for individual behavior. Unlike in the previous treatments where individ-

\footnotetext{
${ }^{20}$ The untranslated Dutch text is: 'Beste Joost, ik weet dat je wacht op een sociale huurwoning en dat je moeilijk je rekeningen kan betalen. Hier heb je $€ 20$. Het is misschien niet veel, maar het is alles wat ik me kan veroorloven. - Opa'
} 
uals needed to post an envelope to benefit someone else, in treatment PI they had to mail an envelope to benefit themselves. Using the same procedure as in our other treatments, we delivered A4-sized envelopes with the logo of Erasmus University Rotterdam to pre-identified rich and poor households. The envelope contained a stamped return envelope with the university's address, information about the Erasmus University Postal Study, and a $€ 5$ note. The latter was included to signal the seriousness of the study.

The task in this treatment was designed to be as similar as possible to that of our other treatments. The letter explained that the aim of the study was to examine "how people in different parts of the Netherlands use the postal service and send letters." All participants had to do was to drop the stamped envelope in a public mailbox. The accompanying letter also promised a payment of $€ 20$, if the envelope was returned within the one month deadline. For more details on the PI treatment see the Online Supplementary Material.

One might expect that return rates for the rich in this treatment would be lower than those in the previous treatments, given their low marginal utility from money. It is less clear what to expect for the poor. On the one hand, they can obtain $€ 20$ without any feelings of guilt. On the other hand, as we saw, the pressure they are under may make them view this task as one of low priority, and not return the stamped envelope.

Poor households posted $60 \%$ of the pre-stamped envelopes, while rich households posted $69 \%$. The difference is not statistically significant (Fisher Exact, $p=0.51 ; N=90$ ). Given the higher marginal utility from money for the poor, the lack of a significant difference in return rates might be interpreted as further evidence of the pressure the poor are under.

Additional evidence consistent with this interpretation comes from analyzing the time it took the rich and poor to return envelopes. On average, the poor take significantly longer to return envelopes than the rich: 13.15 vs. 8.24 days, excluding the PI treatment (MannWhitney, $\left.p=0.08, N_{\text {rich }}=146, N_{\text {poor }}=68\right)$. The same can be observed in the PI treatment, where the poor take on average 12.78 days to return the envelope vis-a-vis 7.29 days for the rich (Mann-Whitney, $p<0.01, N_{\text {rich }}=31, N_{\text {poor }}=27$ ). The same analysis broken down by treatment can be found in the Online Supplementary Material.

It is worth noting that the behavior of the rich in the PI treatment casts further doubt on the widely held belief that the rich only care for themselves. The difference in return of non-cash envelopes in the main experiment and envelopes in the PI treatment is $16.67 \%$ for the rich. That is, if anything, the rich return more envelopes if it benefits someone else than if it benefits themselves. For the poor, the difference is $-12.22 \%$. This difference-in-difference is 28.89 percent and is highly significant $(p<0.01$; see the Online Supplementary Material for details). 


\section{Conclusion}

Our study contributes novel evidence to the centuries-old debate on the relative pro-sociality of the rich. Although several studies have previously explored the behavior of the rich, the evidence on their relative pro-sociality was not conclusive due to a host of reasons, including endogeneity and selection problems. Our research strategy differs markedly from that in previous studies. The use of a natural field experiment in combination with household-level data provided by CBS Netherlands imply that we do not have to rely on self-selected samples or the use of self-reported measures of pro-sociality.

Our raw data reveal that, in contrast to popular perceptions and to recent claims by the broad social-science community, the rich are overall more than twice as likely as the poor to return the envelope to the intended recipient, despite there being no repercussions from not returning it. The difference is robust to controlling for a range of socio-economic characteristics obtained from CBS Netherlands. The variation provided by our experiment also allows us to answer the more important question: Why do the rich choose behaviors that are more pro-social? Are they less selfish or, as we argued in the introduction about the contrasting findings in the literature, is there an endogeneity problem in our experiment as well?

Using a simple model, we identified that the greater occurrence of the seemingly selfish behavior of the poor in our sample can be accounted by two effects. First, for those who truly intend to return the envelope the chore of doing so gets more difficult to accomplish as time gets farther from their payday and the stresses of living in poverty build. Second, for the envelopes of potential monetary value to the accidental recipient, we find that the higher marginal utility of money for the poor affects their willingness to return these envelopes. When we account for both of these mitigating factors-which themselves are the byproduct of poverty-we find no statistically significant difference in the pro-social tendencied of the rich and poor.

These findings point to several valuable avenues for future research. First, they highlight the importance of collecting data that will help explore issues of endogeneity, and thus identify whether preferences, and not simply behaviors, differ among social classes. Second, it is important to carry out additional studies in different populations with different customs, and more or less entrenched social and economic class structures. The Netherlands, for instance, ranked as the fifth least corrupt country in the world in 2016, making the wealthy there potentially less representative of wealthy people globally. Third, our study contributes to a recent literature examining the negative effects of poverty on individual behavior, by showing that financial pressure can crowd out pro-social behavior. More research, both in the lab and the field, is needed to better understand the channels through which poverty may affect the propensity of individuals to behave pro-socially.

We end our discussion by returning to the famous incident in which Ernest Hemingway 
told his friends over lunch: "I'm getting to know the rich," and Mary Colum, a well-known literary critic at the time, responded that Hemingway is likely to be disappointed by what he finds, replying, "The only difference between the rich and other people is that the rich have more money." Our results support Mary Colum's view in the sense that we find no differences in the pro-social preferences of the rich from those of the poor. Lest our findings be misinterpreted, this does not absolve the rich for their selfish behavior when they evade taxes and break the law. What it suggests is that the rich are no different than the rest: if we were to put the poor in their place, they would likely behave similarly.

Finally, our results provide an important caveat to Colum's statement. While the difference in other arenas (such as tax evasion or charitable giving) may hinge on the fact that the rich have more money, in our study, the key fact seems to be that the poor have so little money. Our study therefore suggests an important notion: the financial pressures of poverty may make poor individuals sometimes behave less pro-socially. This hypothesis has potentially important, policy-relevant consequences for society at large, illustrating a new mechanism through which poverty may undermine social welfare. 


\section{References}

Andreoni, J. (2006). Philanthropy. Handbook of the economics of giving, altruism and reciprocity, 2, 1201-1269.

Andreoni, J. (2015). Economics of charity and philanthropy. In J. D. Wright (Ed.), International Encyclopedia of the Social \& Behavioral Sciences, 2nd Edition, volume 3 (pp. 358363). Oxford: Elsevier.

Andreoni, J. and Bernheim, B. (2009). Social image and the 50-50 norm: A theoretical and experimental analysis of audience effects. Econometrica, r77(5), 1607-1636.

Andreoni, J., Erard, B., and Feinstein, J. (1998). Tax compliance. Journal of Economic Literature, 36(2), 818-860.

Andreoni, J., Goldman, M., and Maras, M. (2015). Holier than thou? A natural field experiment on social information in charitable giving. In Academy of Management Proceedings, volume 2015, (pp. 15617). Academy of Management.

Andreoni, J. and Miller, J. (2002). Giving according to garp: An experimental test of the consistency of preferences for altruism. Econometrica, 70, 737-753.

Andreoni, J. and Payne, A. A. (2013). Charitable giving. Handbook of Public Economics, 5, $1-50$.

Andreoni, J. and Petrie, R. (2004). Public goods experiments without confidentiality: A glimpse into fund-raising. Journal of Public Economics, 88(7), 1605-1623.

Atkinson, A., Piketty, T., and Saez, E. (2011). Top incomes in the long run of history. Journal of Economic Literature, 49(1), 3-71.

Auten, G., Sieg, H., and Clotfelter, C. (2002). Charitable giving, income, and taxes: An analysis of panel data. American Economic Review, 92(1), 371-382.

Bauer, R., Gneezy, U., and Smeets, P. (2015). Giving behaviour of millionaires. Proceedings of the National Academy of Sciences, 112(3), 10641-10644.

Berg, S. A. (2016). Max Perkins: Editor of Genius. New American Library, New York.

Camerer, C. (2015). Handbook of experimental economic methodology, chapter The promise and success of lab-field generalizability in experimental economics: A critical reply to Levitt and List. Oxford University Press, USA.

Carvalho, L. S., Meier, S., and Wang, S. W. (2016). Poverty and economic decision-making: Evidence from changes in financial resources at payday. The American Economic Review, $106(2), 260-284$. 
Christian, C. (1994). Voluntary compliance with the individual income tax: Results from the 1988 TCMP study. The IRS Research Bulletin, 1500(9-94), 35-42.

Cox, D. (1984). Raising revenue in the underground economy. National Tax Journal, 37(3), $283-288$.

DellaVigna, S., List, J. A., and Malmendier, U. (2012). Testing for altruism and social pressure in charitable giving. Quarterly Journal of Economics, 127(1), 1-54.

Dubois, D., Rucker, D. D., and Galinsky, A. D. (2015). Social class, power, and selfishness: When and why upper and lower class individuals behave unethically. Journal of Personality and Social Psychology, 108(3), 436.

Economist (2010). The rich are different from you and me: They are more selfish. July 29, available at: http://www.economist.com/node/16690659.

Economist (2014). Inequality in the Netherlands: A capital issue. July 28, available at: http://www.economist.com/news/europe/21605955-how-large-differenceswealth-have-begun-new-tax-debate-capital-issue.

Eisenberg, N., Fabes, R. A., Miller, P. A., Fultz, J., Shell, R., Mathy, R. M., and Reno, R. R. (1989). Relation of sympathy and personal distress to pro-social behavior: A multimethod study. Journal of Personality and Social Psychology, 57, 55 - 66.

Erkal, N., Gangadharan, L., and Nikiforakis, N. (2011). Relative earnings and giving in a real-effort experiment. The American Economic Review, (7), 3330-3348.

Fehr, E. and Schmidt, K. (1999). A theory of fairness, competition and cooperation. Quarterly Journal of Economics, 114, 817-868.

Fisman, R., Kariv, S., and Markovits, D. (2007). Individual preferences for giving. The American Economic Review, 97(5), 1858-1876.

Francis, G. (2012). Evidence that publication bias contaminated studies relating social class and unethical behavior. Proceedings of the National Academy of Sciences, 109(25), E1587.

Frank, R. (2011). Are the rich more selfish than the poor? Wall Street Journal, August 11, available at: http://blogs.wsj.com/wealth/2011/08/11/are-the-rich-more-selfishthan-the-poor/.

Franzen, A. and Pointner, S. (2012). The external validity of giving in the dictator game: A field experiment using the misdirected letter technique. Experimental Economics, DOI 10.1007/s10683-012-9337-5. 
Fuentes-Nieva, R. and Galasso, N. (2014). Working for the Few: Political capture and economic inequality, volume 178. Oxfam.

Goleman, D. (2013). Rich people just care less. The New York Times, October 5, available at: http://opinionator.blogs.nytimes.com/2013/10/05/rich-people-just-care-less/?

Guinote, A., Cotzia, I., Sandhu, S., and Siwa, P. (2015). Social status modulates prosocial behavior and egalitarianism in preschool children and adults. Proceedings of the National Academy of Sciences, 112(3), 731-736.

Haushofer, J. and Fehr, E. (2014). On the psychology of poverty. Science, 344(6186), 862-867.

Hoffman, E., McCabe, K., and Smith, V. (1996). Social distance and other-regarding behavior in dictator games. American Economic Review, 86(3), 653-660.

Hooker, L. (2015). Does money make you mean? BBC News, March 16, available at: http://www.bbc.com/news/magazine-31761576.

Howitt, D., Craven, G., Iveson, C., Kremer, J., McCabe, J., and Rolph, T. (1977). The misdirected letter. The British Journal of Social and Clinical Psychology, 16, 285-286.

Karlan, D. and List, J. A. (2007). Does price matter in charitable giving? Evidence from a large-scale natural field experiment. The American Economic Review, 97(5), 1774-1793.

Karlan, D., Ratan, A. L., and Zinman, J. (2014). Savings by and for the poor: A research review and agenda. Review of Income and Wealth, 60(1), 36-78.

Keizer, K., Lindenberg, S., and Steg, L. (2008). The spreading of disorder. Science, 322(5908), $1681-1685$.

Konow, J. (2000). Fair shares: Accountability and cognitive dissonance in allocation decisions. The American Economic Review, 1072-1091.

Korndörfer, M., Egloff, B., and Schmukle, S. C. (2015). A large scale test of the effect of social class on prosocial behavior. PloS One, 10(7), e0133193.

Kraus, M. W., , P. K., Mendoza-Denton, R., Rheinschmidt, M. L., and Keltner, D. (2012). Social class, solipsism, and contextualism: how the rich are different from the poor. Psychological Review, 119(3), 546.

Levitt, S. D. and List, J. A. (2007). What do laboratory experiments measuring social preferences reveal about the real world? The Journal of Economic Perspectives, 21(2), $153-174$.

Mani, A., Mullainathan, S., Shafir, E., and Zhao, J. (2013). Poverty impedes cognitive function. Science, 341(6149), 976-980. 
McDonald, I. M., Nikiforakis, N., Olekalns, N., and Sibly, H. (2013). Social comparisons and reference group formation: Some experimental evidence. Games and Economic Behavior, $79,75-89$.

Mullainathan, S. and Shafir, E. (2013). Scarcity: Why having too little means so much. Macmillan.

Piff, P., Kraus, M., Cote, S., Cheng, B., and Keltner, D. (2010). Having less, giving more: The influence of social class on prosocial behavior. Journal of Personality and Social Psychology, 99, $771-784$.

Piff, P., Stancato, D., Cote, S., Mendoza-Denton, R., and Keltner, D. (2012). Higher social class predicts increased unethical behavior. Proceedings of the National Academy of Sciences, USA, 109, 4086-4091.

Proud, A. (2015). When did the rich become so utterly horrible? The Telegraph, March 30, available at: http://www.telegraph.co.uk/men/thinking-man/11500107/When-didthe-rich-become-so-utterly-horrible.html.

Roth, J., Scholz, J., and Witte, A. (1989). Taxpayer Compliance, Vol. 1: An Agenda for Research. Philadelphia, University of Pennsylvania Press.

Saez, E. and Zucman, G. (2016). Wealth inequality in the united states since 1913: Evidence from capitalized income tax data. Quarterly Journal of Economics, 131(2), 519-578.

Schervish, P. G. and Havens, J. J. (2003). New findings on the patterns of wealth and philanthropy. Social Welfare Research Institute, Chestnut Hill.

Shah, A. K., Mullainathan, S., and Shafir, E. (2012). Some consequences of having too little. Science, 338(6107), 682-685.

Stoop, J. (2014). From the lab to the field: Envelopes, dictators and manners. Experimental Economics, 17(2), 304-313.

Sullivan, P. (2017). Who are the richest of the rich? The New York Times, February 19, available at: https://www.nytimes.com/2017/02/19/your-money/who-are-the-richest-of-therich.html.

Trautman, S., van de Kuilen, G., and Zeckhauser, R. (2013). Social class and (un)ethical behavior: Evidence from a large population sample. Perspectives on Psychological Science, $8(5), 487-497$.

Volker, B., Mollenhorst, G., Steenbeek, W., Schutjens, V., and Flap, H. (2015). Lost letters in Dutch neighborhoods: A field experiment on collective efficacy. Social Forces, sov106. 
Wang, L. and Murnighan, J. K. (2014). Money, emotions, and ethics across individuals and countries. Journal of Business Ethics, 125(1), 163-176.

Warner, J. (2010). The charitable-giving divide. The New York Times Magazine, August 20, available at: http://www.nytimes.com/2010/08/22/magazine/22FOB-wwln-t.html?

Wood, M. (1998). Socio-economic status, delay of gratification, and impulse buying. Journal of Economic Psychology, 19(3), 295-320. 